ing on the history of the human race, that of the relation of culture to climate. Much as has been done, the author would be the last to say that more than a breaking of the ground has been accomplished. He himself is as busily engaged now as before, deriving evidence from all sources available to him, as witness the recent papers on the relation of climate and civilization, work and weather, in Harper's Magazine, forecast doubtless of more extensive study of the same kind.

A single matter of book-making should be especially mentioned. In a note to the reader, following the table of contents, a list of segregations of chapters is given for the direction of those more especially interested in one field of thought than another. Such schemes are helpful in these days of much publication.

Francis E. Lloyd

MCGILL UNIVERSTTY

\section{THE PROCEEDINGS OF THE NATIONAL} ACADEMY OF SCIENCES

(NUMBERS 1-4)

Four numbers of the Proceedings of the National Academy of Sciences have now been issued. These contained in 258 pages a total of 70 articles, including the report of the autumn meeting of the Academy. The average length of the contributions was therefore 3.7 pages, which lies well within the limit of 6 pages, or 2,500 words, set by the editors.

The number of articles in the various branches of science is as follows:

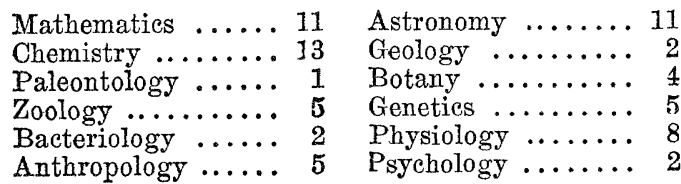

The inadequate representation of certain sciences, such as physics, geology and pathology, is largely accidental, as many authors in these fields have indicated their intention of contributing to the Proceedings.

The arrangement of the articles according to geographical distribution into Eastern, Middle West, and Pacific also shows a reasonable distribution over the whole United States. The figures are:
Eastern ...35 Middle west ...21 Pacific ...13

The Pacific figures show the activities of the great Lick and Mt. Wilson observatories in astronomy; and the Middle West has an exceptional representation in mathematics.

A number of the papers which have appeared in the Proceedings were read before the Academy at its autumn meeting and have therefore appeared in abstract in ScIENcE. Without making exceptions in the case of these papers, the contents of the first four issues of the Proceedings may be outlined as follows:

Astronomy.-An analysis of the radial velocities of nebulæ by W. W. Campbell shows that the planetary nebulæ are on the average moving much faster than the helium stars, which are supposed to be nearest to the nebular condition; and this leads to the suggestion that these nebulæ may have arisen by the collision of fast moving stars with resisting media.

H. D. Curtis, from a study of photographs of nebulæ taken at various times throughout a period of thirteen years, concludes that there are upon the plates no evidences of internal motion and little if any of proper motion, indicating great distance and enormous size for these objects.

The announcement of the discovery of the ninth satellite of Jupiter is made by $\mathrm{S}$. B. Nicholson.

R. E. Wilson reports abnormally high radial velocities (some $250 \mathrm{~km}$. per sec.) for nebulæ in the Magellanic Clouds, and calls attention to the importance of determining the velocities of stars in the clouds to ascertain whether the clouds as a whole may have such a velocity.

Kapteyn's theory that the universe is mainly composed of two great streams of stars is strongly supported by a statistical study of stellar radial velocities by J. C. Kapteyn and W. S. Adams. New observations of faint stars show that the streams extend to the greatest distances for which data are available.

A. van Maanen's measures of stellar parallaxes with the sixty-inch reflector are apparently of very high precision. 
Solar physics is represented by a number of contributions. G. E. Hale and H. D. Babcock seek with the aid of the Stark effect to measure the potential-gradient in the solar atmosphere, and find that at the level in question it does not exceed two hundred times the average value in the earth's atmosphere. A study of the flash spectrum of the uneclipsed sun leads W. S. Adams and E. G. Burwell to infer that the observations without an eclipse represented a lower level than those during eclipse, and that there is a considerable gain in accuracy (owing to the greater linear scale of the Mt. Wilson photographs); the results do not support the hypothesis of anomalous dispersion as explanatory of solar phenomena. C. E. St. John offers an extensive critique of this hypothesis, and concludes that the theory which bases the shifts in the spectral lines on supposed velocities in the solar atmosphere is far more satisfactory than that which explains these shifts by anomalous dispersion.

That spherical aberration may be induced in a thoroughly corrected objective by rapidly changing temperatures is noted by F. Schlesinger, and mechanical devices for removing the inequalities of temperature are described.

C. E. St. John and H. D. Babcock have examined the spectral lines in the iron arc and have discovered that the wave-lengths of many of the lines depend upon the portion of the arc from which the light is taken, a fact which must be recognized in fixing precise standards in spectroscopy.

Chemistry.-Revisions of the atomic weights of cadmium, lead and praseodymium are reported by G. P. Baxter and various collaborators. The values obtained are: cadmium, 112.417; lead, 207.20; praseodymium, 140.92; $\mathrm{Cl}=35.457$ and $\mathrm{Ag}=107.880$ being assumed in the computations. There appeared to be no difference between specimens of lead from different geographical sources.

W. A. Jacobs and M. Heidelberger offer a proof of Dimroth's monomolecular formulas for $p$-aminophenylmercuric compounds as against Pesci's more complicated formulas.

P. A. Levene and F. B. La Forge state that the 2-aminohexose isolated by them and named chrondrosamine has the configuration of either 2-altrosamine or of 2-allosamine.

In a series of papers on potassium ammono argentate, barate, calciate, and sodate, on metallic salts of ammono acids, and on ammonobasic iodides of aluminium, E. C. Franklin reports further progress on his extensive investigation on the analogies between aqueous and liquid-ammonia solutions.

The use of J. J. Thomson's electron theory of valence and of various modifications of that theory is discussed by J. Stieglitz, both descriptively and (with collaborators) experimentally, in papers on the molecular rearrangements of triphenylmethane derivatives with the conclusion that the original Thomson theory is extremely useful, but that its newer modifications are not necessary so far as the present investigation is concerned.

An extended investigation of the effects of lipases in hydrolyzing esters is described by K. G. Falk. He comes to the conclusion that the specific character of these effects is due in some cases to the influence of the ester on the enzyme in causing its coagulation or precipitation, and in other cases to the influence of the enzyme on the ester arising from the presence in the former of special groupings similar to those in amino-acids and peptides, which also bring about hydrolysis of esters, as shown by the experiments of the author made in collaboration with M. L. Hamlin.

E. W. Washburn and J. W. Read show that the freezing-points and the eutectic point of solutions, however concentrated, of two substances which conform to the laws of ideal solutions can be calculated; and they communicate experiments which show close concordance of the observed eutectic points with those calculated. They derive from their considerations the following quantitative principle relating to solubility: When a crystalline substance $A$ is dissolved in any solvent $B$ with which it forms an ideal solution, its solubility is independent of the nature of the solvent $B$, and depends merely on the temperature and on the melting-point and heat of fusion of the crystals $A$.

E. W. Washburn and E. B. Millard show that the electrolysis of a solution of cesium. 
chloride containing raffinose at low concentration is attended by a decrease in the anodeportion, and an increase in the cathode-portion, of the ratio of the quantity of water to that of raffinose. This result proves that there is a net transfer of water to the cathode, and therefore that the cesium ion is hydrated to a greater extent than the chloride ion. The cesium ion is shown to be the least hydrated of the ions of all the alkali elements previously studied.

Geology.-A voyage through the Pacific to visit coral reefs for the purpose of discriminating between various theories proposed to account for their formation convinced W. M. Davis that Darwin's original theory of subsidence gives by far the most satisfactory explanation of all the barrier reefs he visited.

G. F. Becker proposes to consider the earth as a heat engine competent to bring about all the dynamical effects with which geology has to deal by the stress and strains which would arise during cooling, due to local differences of the tendency of the surface layer to lose heat.

Paleontology. - The hypothesis advanced by C. D. Walcott that bacteria probably were an important factor in the deposition of the Algonkian limestones has received strong support by his discovery of bacteria resembling Micrococci in the fossil alga of the Newland limestone.

Botany.-C. J. Chamberlain presents a phylogenetic study of Cycads based upon detailed field-work extending over a decade.

Phoradendron is classified by $\mathrm{W}$. Trelease into two primary groups: Boreales containing 60 and Equateriales containing 202 differentiable forms, most of which he regards as species.

From a study of the morphology and relationships of Podomitrium malaccense D. H. Campbell decided that Podomitrium is much more like Blyttia than like Metzgeria and should be placed in the Blyttiaceæ rather than Aneuraceæ.

That the loss of viability in seeds with storage is a matter of coagulation of cell proteins, and that there is a possibility of determining a quantitative statement of the significance of various storage conditions, is indicated by a study of the germination of wheat by W. Crocker and J. F. Groves.

Zoology.-Experiments on the fertilizing power of sperm dilutions of Arbacia indicate to F. R. Lillie that the loss of fertilizing power is due not to loss of motility of the spermatozoa, but to loss of their activating substance, which he designates as sperm receptors; light is also thereby thrown on the process of fertilization.

C. Zeleny and E. C. Faust investigate dimorphism in size of spermatozoa with its relation to the chromosomes, and come to the conclusion that such dimorphism must exist very generally and is probably the result of chromosomal dimorphism present in the spermatids.

R. Goldschmidt reports experiments which point to the probability that the general processes of spermatogenesis are necessary reactions of the cells to a systematic regulation of the osmotic conditions on the part of the follicular membrane; the individual specific processes are caused by the specific properties of the reacting cells.

Extensive experiments on flounders show that their remarkable ability to simulate the color and pattern of the background against which they rest is controlled by their visual perception of the background and that the rapidity of the adaptation to surroundings is greatly increased by frequent practise, according to S. O. Mast.

A quantitative ecological study of the Madreporian corals of the fringing reef of Maer Island is presented by A. G. Mayer; the destructive effects of temperature, silt, etc., are discussed.

Genetics.-C. B. Davenport has two articles upon the feebly inhibited: I. Violent temper and its inheritance; II. Nomadism or the wandering impulse with special reference to heredity. The nomadic instinct is fundamental in man, but is inhibited in well-regulated individuals. The tendency to outbursts of temper is probably a dominant trait.

By studying quantitatively the color patterns of a race of rabbits bred especially for the purpose W. E. Castle and P. B. Hadley obtain what they regard as conclusive evidence 
against the idea of unit-character constancy or "gametic purity."

Experiments on self-sterility incline E. M. East away from simple Mendelian formulas of the type suggested by Correns and toward Jost's idea of "Individual stoffe" and a nearMendelian interpretation.

In an attempt to analyze the normal variation of an organism from the standpoint of Entwicklungsmechanik, R. Pearl and F. M. Surface study growth and variation in maize. They find that the differences in the manner of growth of individual plants and of groups of plants can not be explained as the effect of environmental factors, but should be regarded as due to internal factors; they regard the differences as due to independent Mendelian factors distributed at random in any population of open fertilized maize plants.

Bacteriology.-W. A. Jacobs and M. Heidelberger report upon a new group of bactericidal substances obtained from hexamethylenetetramine.

In experiments upon B. coli, E. O. Jordan finds an instance of bacterial mutation which seems to fulfil the requirements of appearing suddenly without intermediate stages, of being irreversible, of comprising change of two characters, and of not involving all of the cells of the parent strain.

Physiology. - In a series of short notes F. G. Benedict (with collaborators) sets forth these results: The gaseous metabolic processes of vegetarians are qualitatively and quantitatively essentially those of non-vegetarians of similar height and weight. There is a distinct tendency for athletes to have a measurably larger basal resting metabolism than non-athletes. Men disclose a basal metabolism some 5 or 6 per cent. greater than women of similar height and weight. The general conclusion is that the basal metabolism of an individual is a function, first, of the total mass of active protoplasmic tissue, and second, of the stimulus to cellular activity, existing at the time the measurements are made. The 416-page monograph containing chemical and physiological studies of a man fasting thirtyone days, recently published by the Carnegie Institution, is represented in the Proceedings by a chart indicating the trend of the most important factors measured.

An exposition of a dynamic conception of the organic individual is given by C. M. Child in terms of metabolic gradients. The region of high metabolic rate determining the gradient arises from the differential action of factors external to the organism and becomes the chief determinant of the rate in near-by regions, thus finally dominating the whole individual and affording a basis for the orderly development of the whole which is observed throughout nature.

According to S. Tashiro the nerve impulse is a propagation of chemical change, a propagation due to restoration of an equilibrium disturbed by the increase of metabolism at the point of stimulus and proceeding toward the point where there is less chemical activity as measured by production of carbon dioxide.

J. Loeb and H. Wasteneys find that heliotropism in animals and plants is essentially the same.

Anthropology.-Caribou and related types of culture among the Indians and the diffusion of horse culture among them are treated in two articles by C. Wissler.

A. C. Fletcher reports upon her studies of Indian music.

An examination of Barbados convinces $\mathrm{J}$. W. Fewkes that Barbados had in prehistoric times a large local population whose culture resembled that on the other West Indies.

A. Hrdlička gives an account of the anthropological expeditions sent out to collect material for the exposition at San Diego.

Psychology.-An outline of a point scale for measuring mental ability, a revision of the Binet scale, is given by R. M. Yerkes. The same author sketches the results of his experiments upon color vision in the ring dove.

Mathematics.-L. E. Dickson offers two papers upon his new modular geometry. Two notes on abstract groups are due to G. A. Miller. Point sets and allied Cremona groups are treated by A. B. Coble, and H. S. White gives an account of his investigation of triad systems. The theory of surface is discussed by E. J. Wilczynski and L. P. Eisenhart, and F. L. Hitchcock submits a classification 
of quadratic vector functions. Analysis is represented by a contribution from G. A. Bliss on functions of lines and one from $\mathrm{A}$. Dresden upon the calculus of variations.

Edwin Bidwell Wilson

\section{SPECIAL ARTICLES}

\section{A MODIFICATION OF THE BELLANI POROUS PLATE ATMOMETER}

A RECENTLY renewed and increased interest in the direct measurement of the evaporating power of the air ${ }^{1}$ has brought the atmometer (incorrectly called evaporimeter, etc.) into greater prominence than has heretofore been enjoyed by that instrument. Atmometers are now being used more than ever before, especially in plant physiology, plant and animal ecology, and the agricultural aspect of climatology. ${ }^{2}$ This newer development of atmometry

1 The evaporating power of the air may be thought of as the reciprocal of the resistance offered by the air to evaporation from exposed liquid water. The term is a misnomer to a degree, for evaporation proceeds from a water surface in spite of the conditions obtaining in the surrounding air. Ceteris paribus, the greater is the air pressure, the less rapid is evaporation; the less water is contained in the air the more rapid is evaporation, etc. The term has come into rather general use, however, and may as well stand till a better is suggested; it is logically no worse than the word suction, and, like it, is readily understood by everybody. Condensing power or water supplying power can not here be used in place of resistance, because air without water-vapor offers resistance to evaporation but has no condensing power; it can not deposit water upon a surface, no matter what its pressure may be. The resistance offered by such dry air can be expressed in terms of an equivalent condensing power, however.

2 Livingston, B. E., "The Relation of Desert Plants to Soil Moisture and to Evaporation," Carnegie Inst. Wash. Pub. 50, 1906. Shelford, V. E., "Animal Communities in Temperate America," Geog. Soc. Chicago Bull. 5, 1913, pages 162-65. Livingston, B. E., and L. A. Hawkins, "The Water Relation between Plant and Soil," Carnegie Inst. Wash. Pub. 204, 1915 (the first paper of that publication). Shive, J. W., "An Improved Nonabsorbing Porous Cup Atmometer," Plant World, 18: 7-10, 1915. Livingston, B. E., "Atmometry has emphasized the employment of waterimpregnated solids to furnish the evaporating surface from which the rate of evaporation is studied, and has discouraged the use, for many purposes at least, of the open pan or tank of water so commonly met with in meteorological and general climatological literature. It has thus come about that considerable misunderstanding has arisen as to what atmometry is really aiming at and as to the relative desirability of studying evaporation from one or another kind of evaporating surface.

Of all the different forms of water-impregnated surfaces employed in the study of atmospheric evaporating power, the cylindrical porous clay cup of Babinet ${ }^{3}$ has met with the most favor among biological and agricultural workers, and the standardized porous cups now in general use follow the principle of Babinet's device. This type of atmometer possesses a number of pronounced advantages over the free water surface, when atmospheric evaporating power is to be studied as an environmental condition affecting animals and plants. Among these advantages may be mentioned the fact that the evaporating surface of the cup projects up into the air like most animal and plant surfaces. Thus it does not so readily become clogged, as it were, by its own vapor blanket, as does a horizontal surface. Furthermore, the porous cup instrument is much more readily and precisely read than is the open tank, and very short time intervals may consequently be employed. I have frequently constructed graphs showing the march of evaporating power by minute or 5-minute rates, a procedure hardly possible with any form of pan atmometer. More important than any other of the advantages here in question, however, is the one depending upon comparative variability of the evaporating surface with and the Porous Cup Atmometer," Plant World, 18: 21-30, 51-74, 95-111, 143-149, 1915 . Livingston, B. E., "Atmospheric Influence upon Evaporation and Its Direct Measurement," Mo. Weather Rev., 1915. McLean, F. T., "Relation of Climate to Plant Growth in Maryland,'" Mo. Weather Rev., 1915.

3 Babinet, J., "Note sur un atmidoscope," Compt. Rend. Paris, 27: 529-30, 1848. 